DOI: $10.18287 / 2542-047 X-2020-6-4-67-71$

УДК 343.14

Научная статья / Scientific article
Дата: поступления статьи / Submitted: 28.09.2020 после рецензирования / Revised: 02.11.2020 принятия статьи / Accepted: 27.11.2020

В. О. Белоносов

Самарский национальный исследовательский университет имени академика С. П. Королева, г. Самара, Российская Федерация E-mail: vladimirbelonosov@yandex.ru

Аннотация: В статье автор анализирует изменения, внесенные в УПК РФ в 2019 году и первой половине 2020 года. Делает вывод, что, несмотря на существенное сокращение гиперактивного законотворчества с 2019 г., качество вносимых изменений оставляет желать лучшего. Продолжают иметь место необоснованные повторения положений общего характера без внесения какой-либо новизны. Предметом регулирования выступают несущественные вопросы, а субъектами - лица, не выполняющие процессуальных функций. Во вносимых поправках игнорируются права и свободы граждан, они принимаются в интересах правоохранительных ведомств и носят формально-бюрократический характер. Все это не способствует стабильности законодательства и уважительному отношению к закону, искажается смысл законности. В этих условиях автор предлагает вернуться к правовому пониманию законности, возрождению морально-этических начал уголовно-процессуальной деятельности, возобновлению и активизации дискуссий по теме защиты прав и свобод личности в уголовном судопроизводстве.

Ключевые слова: уголовный процесс, УПК РФ, законотворчество, федеральный закон, Конституционный Суд РФ, толкование, изменения, статья.

Цитирование. Белоносов В. О. Об уголовно-процессуальном законотворчестве в современных условиях // Юридический вестник Самарского университета. 2020. Т. 6, № 4. C. 67-71. DOI: https://doi.org/10.18287/2542047Х-2020-6-4-67-71.

Информация о конфликте интересов: автор заявляет об отсутствии конфликта интересов.

V. O. Belonosov

Samara National Research University, Samara, Russian Federation E-mail: vladimirbelonosov@yandex.ru

\title{
ON CRIMINAL PROCEDURE LAW-MAKING IN THE MODERN CONTEXT
}

\begin{abstract}
The article analyzes the changes made to the CPC in 2019 and the first half of 2020. It is concluded that despite a significant reduction in overactive legislative drafting since 2019, the quality of the changes made leaves much to be desired. Unjustified repetition of general provisions without any novelty continues to occur. Substantive issues are the subject of regulation, while the subjects are persons who do not perform procedural functions. The amendments ignored citizens' rights and freedoms, were adopted in the interests of law enforcement agencies and were formal and bureaucratic in nature. All this does not contribute to the stability of legislation and respect for the law, distorting the meaning of legality. Under these conditions, it is proposed to return to a legal understanding of the law, to revive moral and ethical principles of criminal procedure, to resume and intensify discussions on the protection of individual rights and freedoms in criminal proceedings.
\end{abstract}

Key words: criminal procedure, CPC RF, lawmaking, federal law, Constitutional Court RF, interpretation, changes, article.

Citation. Belonosov V. O. Ob ugolovno-protsessual'nom zakonotvorchestve v sovremennykh usloviiakh [On criminal procedure law-making in the modern context]. Iuridicheskii vestnik Samarskogo universiteta [Juridical Journal of Samara University], 2020, Vol. 6, no. 4, pp. 67-71. DOI: https://doi.org/10.18287/2542-047X-2020-6-4-67-71 [in Russian]. Information about the conflict of interests: author declares no conflict of interests.

\section{ИНФОРМАЦИЯ ОБ АВТОРЕ / INFORMАТION ABOUT THE AUTHOR}

(C) Владимир Олегович Белоносов - доктор юридических наук, доцент, профессор кафедры уголовного процесса и криминалистики, Самарский национальный исследовательский университет имени академика С. П. Королева, 443086, Российская Федерация, г. Самара, Московское шоссе, 34.

Тема докторской диссертации: «Толкование норм права в системе теоретической и практической деятельности в сфере уголовного судопроизводства». Автор более 130 научных работ, в том числе монографии «Проблемы толкования норм уголовно-процессуального права России» (2006). Ряд научных трудов написан в соавторстве: «Проблемы современного отечественного уголовного процесса, судебной и прокурорской деятельности» (2016).

Область научных интересов: толкование норм уголовно-процессуального права.
(C) Vladimir O. Belonosov - Doctor of Law, associate professor, professor of the Department of Criminal Process and Criminalistics, Samara National Research University, 34, Moskovskoye shosse, Samara, 443086, Russian Federation.

Subject of Doctoral thesis: «Interpretation of the norms of law in the system of theoretical and practical activities in the field of criminal justice». Author of more than 130 scientific works, including monograph: «Problems of interpretation of norms of criminal procedural law of Russia» (2006). A number of scientific papers written in collaboration: «Problems of modern domestic criminal process, judicial and prosecutorial activity» (2016).

Research interests: interpretation of the rules of criminal procedure. 
Мы продолжаем внимательно следить за ежегодными изменениями уголовно-процессуального законодательства [1; 2]. В 2019 г. УПК РФ менялся 11 законами и корректировался 2 постановлениями Конституционного Суда РФ. А всего за 18 лет с момента своего принятия в декабре 2001 г. по декабрь 2019 г. УПК РФ менялся 257 законами и корректировался 29 постановлениями Конституционного Суда РФ, т. е. 286 нормативными правовыми актами. Такое состояние мы охарактеризовали как гиперактивное законотворчество со всеми отсюда вытекающими отрицательными последствиями.

Но в 2019 г. произошло существенное снижение гиперактивного уголовно-процессуального законотворчества на $45 \%$. Если в 2018 г. было принято 20 законов, изменяющих УПК РФ, то в 2019 г. только 11. Такие результаты оказались неожиданно положительными, ибо гиперактивное законотворчество не улучшало законодательства, отрицательно сказывалось на правоприменении, обучении, издательской деятельности; носило не демократический, а репрессивно-бюрократический характер, принималось в интересах правоприменительных ведомств.

По итогам 5 месяцев 2020 г. принято 5 законов по изменению подследственности и подсудности. По предварительным данным, начатая в 2019 г. тенденция на снижение законотворчества имеет шансы продолжиться, но окончательные выводы делать пока преждевременно. 2020 г. лучше всего анализировать по итогам его окончания.

Намерение ужесточить практику внесения поправок в УПК впервые было сформулировано на парламентских слушаниях в Совете Федерации 22 апреля 2016 г., на которых депутаты приняли решение о внесении поправок в УПК не более 1 раза в год [3, с. 11]. Оно было продиктовано осознанием самими депутатами, что бессистемное внесение поправок в УПК искажает его внутреннюю логику, смысл норм и институтов, отражает ведомственные интересы, подрывает стабильность законодательства и уважительное отношение к закону. Естественно, что они не смогли достичь практики внесения поправок не более 1 раза в год, но определенные результаты нормализации объема законотворчества начали проявляться только с 2019 г.

Такого относительно спокойного уровня уголовно-процессуального законотворчества (11 законов в год) не наблюдалось с 2008 г. Тем не менее его качество продолжает оставаться неоднозначным. Больше всего поправок касалось изменений подследственности и подсудности. В 2019 г. таких законов принято 5 (Федеральные законы от 1 апреля 2019 г. № 46-ФЗ, от 26 июля 2019 г. № 206-Ф3 и № 209-Ф3, от 4 ноября 2019 г. № 354-Ф3, от 27 декабря 2019 г. № 500-Ф3), что составляет 45,4 \%. Но это вынужденные изменения, которые отражают изменения, произошедшие в УК РФ. Анализировать характер этих изменений в рамках уголовно-процессуальных отношений нецелесообразно, но следует отметить их общий усиливающийся репрессивный характер, что связано с появлением и регламентацией новых составов преступлений.

Ряд внесенных изменений в УПК носит формально-бюрократический, несущественный характер. Например, федеральный закон от 6 марта 2019 г. № 21-Ф3 внес дополнение в ч. 5 ст. 108 УПК, дополнив межгосударственным розыском объявление обвиняемого в международный розыск. Хотя международный и межгосударственный розыски может быть чем-то и отличаются, но по своей сути это понятия тождественные, различающиеся формально-бюрократическими деталями, которые не добавляют прав и свобод гражданам, но предназначены для субъектов оперативной, а не уголовно-процессуальной деятельности.

Другой пример. Законом от 3 июля 2019 г. № 160-Ф3 внесены два изменения. Во-первых, список судей в п. 4 ч. 1 ст. 448 УПК был дополнен словами «районного суда, мирового суда». Во-вторых, в п. 5 ч. 1 ст. 448 УПК абстрактное словосочетание «иные судьи» заменено на «судьи конституционного (уставного) суда субъекта РФ». В пояснительной записке к этому законопроекту сказано, что предлагаемый законопроект обесnечит оптимизаџию возбуждения уголовного дела в отношении судьи районного суда и мирового судьи, а также повысит гарантию их независимости.

На протяжении длительного времени в УПК (с 2001 г.), в Законе РФ «О статусе судей в Российской Федерации» (с 1992 г.), в Федеральном законе РФ «Об органах судейского сообщества в Российской Федерации» (с 2002 г.) судьба судей районных судов относилась к компетенции квалификационной коллегии судей субъектов Российской Федерации. А в определении Конституционного Суда РФ от 1 октября 2009 г. № 1042-О-О [4] прямо указано, что уголовные дела в отношении судей районных судов возбуждаются только с согласия квалификационной коллегии судей соответствующего субъекта РФ.

Если в 2019 году в стране к уголовной ответственности было привлечено 17 судей, то по состоянию на сентябрь 2020 года - 7 судей [5]. Не совсем понятно, в чем заключается оптимизация возбуждения уголовных дел? А по поводу гарантии независимости судей вообще неудобно говорить после того, когда в 2020 году независимость судей даже конституционного суда поставлена под сомнение. Отсюда вопросы: так ли уж были необходимы изменения, рассчитанные на единичные случаи правоприменения, когда состояние судебной системы вызывает самую серьезную критику; есть ли какая-то польза от этих изменений гражданам?

Неоднозначно воспринимаются дополнения, вносимые законом от 2 августа 2019 г. № 309-Ф3, об отказе в удовлетворении заявления об отводе, что делает невозможным подачу повторных аналогичных заявлений тем же лицом по тем же основаниям на этапе предварительного расследования, но допустимым в суде. В такой регламен- 
тации нет ничего принципиально нового, так как эти положения уже закреплены в ч. 2 ст. 120, ч. 1 ст. 125 УПК. Поэтому вновь вводимое уголовнопроцессуальное регулирование не представляется вызванным острой необходимостью, а носит дублирующий характер.

Также вопросы вызывает закон от 2 августа 2019 г. № 315-Ф3, который продолжает неоднозначную тему уголовной ответственности индивидуальных предпринимателей и иных субъектов экономической деятельности. В пояснительной записке к этому закону сказано, что он был разработан в целях усовершенствования процессуальных норм, усиления гарантий прав, свобод и личной неприкосновенности обвиняемых, исключения фактов продления сроков содержания под стражей субъектов предпринимательской деятельности в случаях, если по уголовному делу не проводятся активные следственные действия.

Действительно, непроведение активных следственных действий является серьезным нарушением закона, разновидностью пыток, злоупотреблений или всем этим вместе взятым. И суды, безусловно, не должны покрывать такие случаи путем необоснованного продления сроков содержания под стражей. По данным судебной статистики Агентства правовой информации, по уголовным делам всех категорий в суды в 2019 году было подано 217822 ходатайств о продлении срока содержания под стражей, 211248 (96,9 \%) из которых были удовлетворены, а 4761 (2,1 \%) отклонены [6]. По данным Генеральной прокуратуры РФ, из 104927 зарегистрированных в 2019 году преступлений экономической направленности 16756 (15,9\%) были совершены субъектами предпринимательской деятельности [7].

Отличительной особенностью рассматриваемого закона является то, что он обещает более мягко и внимательно относиться к представителям бизнеса, что в целом достойно одобрения. Но почему-то не ко всем, а только к индивидуальным предпринимателям в связи с осуществлением ими предпринимательской деятельности или членам органа управления коммерческой организации в связи с осуществлением ими полномочий по управлению организацией либо в связи с осуществлением коммерческой организацией предпринимательской или иной экономической деятельности по ряду экономических статей. Подобные витиеватые и громоздкие уточнения не только избыточно усложняют законодательство и правоприменение, но и нивелируют достижение заявленных целей. Если за 8 месяцев 2020 г. по сравнению с аналогичным периодом прошлого года возросло количество зарегистрированных преступлений экономической направленности в сфере экономической деятельности, а также количество расследованных преступлений и количество направленных дел в суды на 2,3 \%, но в то же время отмечается снижение экономических преступлений, совершенных субъектами предпринимательской деятельности, на 1,4\% [8]. Хотя эти цифры не дают достаточных оснований считать, что такое снижение произо- шло из-за отказа судов продлевать сроки содержания под стражей в случае непроведения активных следственных действий, тем не менее представляется, что все-таки усиление гарантий прав, свобод и личной неприкосновенности обвиняемых, исключение фактов продления сроков содержания под стражей в случаях непроведения активных следственных действий должны быть одинаковыми для всех граждан, а не только для субъектов предпринимательской деятельности.

Закон от 27 декабря 2019 г. № 498-ФЗ, относя к недопустимым доказательствам любые сведения о добровольном декларировании (что в целом тоже не плохо), излишне в ст. 75 УПК говорит об оперативно-розыскных мероприятиях как недопустимых доказательствах, так как об этом уже сказано в ст. 89 УПК.

Дополнение ст. 140 УПК частью 3 о запрете декларирования быть поводом для возбуждения уголовного дела логичнее было бы поместить после поводов, а не после оснований возбуждения уголовного дела.

В целом запрет изъятия декларации при производстве следственного действия следует оценить положительно. Это второй случай, когда закон добавляет определенные права обвиняемым.

Ряд формальных изменений внесен федеральным законом от 27 декабря 2019 г. № 499-ФЗ. Так, п. 43 ст. 5 УПК приведен в соответствие с п. 1 ст. 140 УПК, в который федеральным законом от 28 декабря 2010 г. № 404-Ф3 в качестве повода для возбуждения уголовного дела добавлено постановление прокурора о направлении материалов в орган предварительного расследования для решения вопроса об уголовном преследовании (спустя 9 лет после своего принятия).

Во-вторых, п. 3 ч. 2 ст. 37 УПК изложен в новой редакции, закрепив полномочие прокурора требовать устранения нарушений федерального законодательства, допущенных при приеме, регистрации, и разрешении сообщений о преступлениях. Но разве это новое полномочие и так ли оно необходимо? Оно давно закреплено в ст. 10, 27, 29, 30 Федерального закона «О прокуратуре РФ», и прокурорские работники его активно выполняют вне зависимости от закрепления в УПК. Статистические данные Генеральной прокуратуры РФ также свидетельствуют об уверенном росте числа требований прокуроров об устранении нарушений закона в порядке п. 3 ч. 2 ст. 37 УПК за 7 месяцев 2020 года (214 461) по сравнению с 7 месяцами 2019 года (195 554) на 9,7 \% [7].

В-третьих, такие же изменения продублированы в ст. 143 УПК.

В-четвертых, доведено до логического завершения положение о том, что любые решения, принимаемые по результатам рассмотрения сообщения о преступлении (ч. 1 ст. 145 УПК), должны направляться прокурору.

Желание привести изменения, предусмотренные федеральным законом от 27 декабря 2019 г. № 498-Ф3 в соответствие с положениями, введенными 9 лет назад федеральным законом от 28 декабря 
2010 г. № 404-Ф3 свидетельствует о том, что прошлый закон, принятый в конце года, был недостаточно хорошо подготовлен, так как не были учтены внутренние системные связи вводимых изменений. Новый закон, принятый тоже в конце года, устраняет недостатки предыдущего неудачного законотворчества. Может быть, неплохо, что недостатки устранены через 9 лет. Но, во-первых, может, их попробовать не допускать, а для этого шире практиковать научные обсуждения? И во-вторых, как показывает практика, законы, принимаемые в конце года, имеют повышенное количество несовершенств.

В 2019 г. два постановления Конституционного Суда РФ (от 17 апреля 2019 г. № 18-П и от 13 июня 2019 г. № 23-П) признали ряд статей УПК частично не соответствующими Конституции РФ. Однако после подробного анализа и убедительной аргументации Конституционный Суд РФ привел рассматриваемые сложные отношения к удивительно простым, логичным, убедительным решениям, в чем проявляется его высокопрофессиональное толкование. Остается только удивляться, почему раныше такие простые и понятные вещи оставались недоступными опытным, в том числе и высокопоставленным юристам: дознавателям, следователям, прокурорам, судьям? Например, разве так уж сложно было понять, что наложение ареста на имущество свидетеля не может продолжаться после вступления приговора в законную силу (постановление Конституционного Суда РФ от 17 апреля 2019 г. № 18-П)? Или кому непонятно, что определение разумного срока уголовного судопроизводства должно исчисляться с момента подачи заявления лица, которому преступлением причинен вред, если производство по делу завершилось обвинительным приговором (постановление Конституционного Суда РФ от 13 июня 2019 г. № 23-П)?

Имеющее место якобы непонимание таких простых вещей, желание придать правовым отношениям иной смысл объясняется не должным пониманием, учитывающим правовые явления во всей их многоаспектности и многогранности, а узким формально-бюрократическим, конъюнктурным, ведомственным подходом, попытками уйти от ответственности за совершенные ошибки и принять желаемое за действительное.

На основании вышеизложенного можно сделать следующие выводы.

В 2019 г. уровень уголовно-процессуального законотворчества снизился на 45 \% и достиг 11 законов, чего не наблюдалось уже 11 лет, что само по себе заслуживает одобрения. По предварительным данным, есть все основания полагать, что этот процесс может продолжиться и в 2020 г., но окончательные выводы делать пока преждевременно. Тем более мы не можем делать вывод о стабильности этой тенденции.

В то же время следует отметить, что большинство новых изменений УПК имеет спорный характер по следующим причинам:

- дублирование давно существующих общих положений без привнесения чего-то нового порождает сомнение в необходимости подобных изменений;
- предметом правового регулирования выступают малозначительные, несущественные правовые отношения, а субъектами - лица, не выполняющие процессуальных функций;

- принятие непроработанных законов, а через много лет приведение их к логической согласованности по малозначительным вопросам в интересах правоприменительных ведомств придает изменениям формально-бюрократический характер.

В качестве существенного недостатка следует указать на забвение категории прав и свобод граждан. Из рассмотренных законов только 2 $(18,2$ \%) имеют определенную демократическую направленность, придавая пусть скромные, но все же дополнительные права участникам уголовного судопроизводства. Оставшейся 81,8 \% законов дополнительных прав гражданам не добавляют, так как они приняты исключительно в интересах правоприменительных ведомств. Причем это устойчиво растущая тенденция: в 2017 г. этот показатель составлял 71 \%, в 2018 г. $-80 \%$ [1, с. 33; 2, с. 49], а в 2019 г. $-81,8 \%$.

Усиливающийся формально-бюрократический подход в правотворчестве в интересах ведомств успешно улавливается правоприменением. Законность постепенно начинает приобретать не только формально-бюрократические, но порой просто репрессивные черты. Это положительно воспринимается правоприменительными органами, которые по своей природе изначально предрасположены к различного рода нарушениям законности. И действительно, если раньше мы только догадывались, что кое-где нарушения законности в уголовном судопроизводстве в принципе возможны, но такие случаи тщательно скрывались, то с 2019 года мы стали свидетелями принципиально нового явления - нескрываемых, широко всеми обсуждаемых, неединичных случаев привлечения к уголовной ответственности, возбуждения уголовного дела, проведения предварительного расследования и вынесения приговора в условиях отсутствия состава преступления, что совершенно недопустимо.

Если не забыты полностью, то сильно отодвинуты назад вопросы правового понимания законности, защиты прав и свобод личности в уголовном судопроизводстве, морально-этических начал этой деятельности. Еще сравнительно недавно (90-е годы XX века-нулевые годы XXI века) в уголовно-процессуальной литературе широко обсуждались права личности в уголовном судопроизводстве. Они были в центре внимания трудов подавляющего большинства авторов, на эту тему защищались диссертации докторские [9; 10] и кандидатские. Теперь об этом перестали говорить, в законодательстве появился ярко выраженный крен в сторону формально-бюрократического и репрессивного подхода, где гарантии прав и свобод граждан становятся недостаточными.

Учитывая, что целью настоящего исследования является постановка диагноза современному состоянию уголовно-процессуального законотворчества, мы не готовы в принципе указы- 
вать на имеющиеся пробелы и противоречия уголовно-процессуального законодательства. Вопервых, это слишком большая тема для отдельного серьезного обсуждения; во-вторых, чтобы не провоцировать новый всплеск гиперактивного законотворчества со всеми его отрицательными последствиями. Мы считаем, что необходимо ввести мораторий на уголовно-процессуальное законотворчество или резко его сократить, оставить все как есть, все равно УПК действует. Вместо усовершенствования отдельных сторон УПК надо принимать новый кодекс. Но доверять это важное дело прежнему законодателю нельзя.

\section{Библиографический список}

1. Белоносов В. О. Правовые проблемы уголовнопроцессуального законотворчества на современном этапе // Правовые проблемы укрепления российской государственности: сб. ст. / науч. ред.: О. И. Андреева, Т. В. Трубникова; отв. секр. И. В. Чаднова. Томск: Изд. Дом ТГУ, 2018. Ч. 79. С. 27-33. DOI: http://doi. org/10.17223/9785946217637/3.

2. Белоносов В. О. О гиперактивном уголовнопроцессуальном законотворчестве // Юридический вестник Самарского университета. 2019. Т. 5, № 4. C. 43-50. DOI: http://dx.doi.org/10.18287/2542047X-2019-5-4-43-50.

3. Качалова О. В. Уголовному процессу обещают перемены // Уголовный процесс. 2016. № 6. C. 11. URL: https://www.elibrary.ru/item.asp?id=26099777.

4. Определение Конституционного Суда РФ от 01.10.2009 № 1042-О-О «Об отказе в принятии к рассмотрению запроса Верховного Суда РФ о проверке конституционности положений п. 5 ч. 1 ст. 448 УПК РФ и п. 3 ст. 16 Закона РФ «О статусе судей в РФ»// Вестник Конституционного Суда РФ. 2010. № 1. URL: https://zknrf.ru/acts/Opredelenie-Konstitutsionnogo-SudaRF-ot-01.10.2009-N-1042-O-O.

5. Локтионова М. Наркотики и взятки: что натворили судьи в 2020 г. // gazeta.ru. URL: http://v-res.in.meizu. com/news/article/2370.html; Судей под суд? // www.9111. ru (дата обращения: 21.09.2020). URL: https://www.9111. $\mathrm{ru} /$ questions/777777777993861.

6. Stat-апи-пресc.pф. URL: www.stat-апи-пресс.pф (дата обращения: 21.09.2020)

7. Статистические данные об основных показателях деятельности органов прокуратуры РФ за июль 2020 г. URL: https://genproc.gov.ru/stat/data/1887646 (дата обращения: 21.09.2020)

8. Статистика и аналитика // Мвд.pф. URL: https://xn-b1aew.xn--p1ai/Deljatelnost/statistics (дата обращения: 21.09.2020)

9. Гранат Н. Л. Правовые и нравственнопсихологические основы обеспечения законности на предварительном следствии: дис. ... д-ра юрид. наук. Москва: Академия МВД РФ, 1992. 589 с.

10. Москалькова Т. Н. Нравственные основы уголовного процесса: стадия предварительного расследования: дис. ... д-ра юрид. наук. Москва: Академия Управления МВД, 1997. 464 c. URL: https://www.dissercat.com/ content/nravstvennye-osnovy-ugolovnogo-protsessa-stadiyapredvarit-rassledovaniya.

\section{References}

1. Belonosov V. O. Pravovye problemy ugolovnoprotsessual'nogo zakonotvorchestva na sovremennom etape [Legal problems of criminal procedure legislation at the modern stage]. In: Pravovye problemy ukrepleniia rossiiskoi gosudarstvennosti: sb. statei. Nauch. red.: O. I. Andreeva, T. V. Trubnikova; otv. sekretar' I. V. Chadnova [Andreeva O. I., Trubnikova T. V., Chadnova I. V. (Eds.) Legal issues of strengthening Russian statehood: collection of papers]. Tomsk: Izd. Dom TGU, 2018, vol. 79, pp. 27-33. DOI: http://doi.org/10.17223/9785946217637/3 [in Russian].

2. Belonosov V. O. O giperaktivnom ugolovnoprotsessual'nom zakonotvorchestve [On hyperactive criminal procedure law-making]. Iuridicheskii vestnik Samarskogo universiteta [Juridical Journal of Samara University], 2019, vol. 5, no. 4, pp. 43-50. DOI: http://dx.doi. org/10.18287/2542-047X-2019-5-4-43-50 [in Russian].

3. Kachalova O. V. Ugolovnomu protsessu obeshchaiut peremeny [Promises to change the criminal process]. Ugolovnyi protsess, 2016, no. 6, p. 11. Available at: https:// www.elibrary.ru/item.asp?id=26099777 [in Russian].

4. Opredelenie Konstitutsionnogo Suda RF ot 01.10.2009 № 1042-O-O «Ob otkaze $v$ priniatii $k$ rassmotreniiu zaprosa Verkhovnogo Suda RF o proverke konstitutsionnosti polozhenii p. 5 ch. 1 st. 448 UPK RF i p. 3 st. 16 Zakona RF "O statuse sudei v $R F$ » [Determination of the Constitutional Court of the Russian Federation № 1042-O-O dated October 01, 2009 «On the refusal to accept for consideration the request of the Supreme Court of the Russian Federation to verify the constitutionality of the provisions of the para. 5 part 1 Article 448 of the Criminal Procedural Code of the Russian Federation and Article 16 of the Law of the Russian Federation «On the Status of Judges in the Russian Federation»]. Vestnik Konstitutsionnogo Suda RF, 2010, no. 1. Available at: https:// zknrf.ru/acts/Opredelenie-Konstitutsionnogo-Suda-RF-ot01.10.2009-N-1042-O-O [in Russian].

5. Loktionova M. Narkotiki $i$ vziatki: chto natvorili sud'i $v 2020 \mathrm{~g}$. [Drugs and bribes: what did the judges do in 2020?]. Retrieved from: www.gazeta.ru. Available at: http:// v-res.in.meizu.com/news/article/2370.html; Sudei pod sud? [A judge in court?]. Retrieved from: www.9111.ru. Available at: https://www.9111.ru/questions/77777777799 3861 (accessed 21.09.2020)

6. Stat-апи-пресc.pф. Available at: www.stat-апи-пресc. pф (accessed 21.09.2020)

7. Statisticheskie dannye ob osnovnykh pokazateliakh deiatel'nosti organov prokuratury $R F$ za iiul' $2020 \mathrm{~g}$. [Statistical data on the main performance indicators of the Russian Prosecutor's Office in July 2020]. Retrieved from: www.genproc.ru. Available at: https://genproc.gov.ru/stat/ data/1887646 (accessed 21.09.2020) [in Russian].

8. Statistika $i$ analitika [Statistics and analytics]. Retrieved from: www.мвд.pф. Available at: https://xn--blaew.xn--p1ai/ Deljatelnost/statistics (accessed 21.09.2020) [in Russian].

9. Granat N. V. Pravovye i nravstvenno-psikhologicheskie osnovy obespecheniia zakonnosti na predvaritel'nom sledstvii: dis. ... d-ra iurid. nauk [Legal and moralpsychological foundations of ensuring legality on preliminary investigation: Doctoral of Laws thesis]. Moscow: Akademiia MVD RF, 1992, 589 p. [in Russian].

10. Moskalkova T. N. Nravstvennye osnovy ugolovnogo protsessa: stadiia predvaritel'nogo rassledovaniia: dis. ... d-ra iurid. nauk [Moral basis of the criminal process: the preliminary investigation stage: Doctoral of Laws thesis]. Moscow: Akademiia Upravleniia MVD, 1997, 464 p. Available at: https:// www.dissercat.com/content/nravstvennye-osnovy-ugolovnogoprotsessa-stadiya-predvarit-rassledovaniya [in Russian]. 